\title{
Kinematics analysis of the throwing pace of the men's javelin champion in the 2017 Summer Universiade
}

\author{
Guocai Ma ${ }^{1, a}$, Bingjun Wan ${ }^{1, b}$ \\ ${ }^{1}$ School of Physical Education, Shaanxi Normal University, Shaanxi 710119, China; \\ awmykx217016ittt@qq.com, bjay00201chou@126.com
}

Keywords: javelin throw; throwing pace; kinematics analysis

\begin{abstract}
Through the analysis and comparison of the throwing pace of the javelin thrower Zhaocun Zheng who participated in the 29th the World University Games and the world outstanding men javelin throwers. This study found that the tilt Angle of the body was larger after the first step and the second step. During the second and third step, the trunk angle is relatively small, resulting in the impact of the intersections. The flexion of his left knee is smaller than the world's elite athletes. It is suggested his left lower limb supported instability, leading to the inability to effectively convert the running speed. This reduces the effective transfer of muscle contractions and momentum, thereby affecting the speed of the javelin.
\end{abstract}

\section{Background}

The javelin throw is one of the fastest growing events in world athletics. In recent years, China's javelin throw has been developing rapidly, and the level of male and female javelin in China has entered the ranks of the world's advanced level. The 29th world university games was held in Taipei, and Zhaocun Zheng won the championship with a score of 91 meters 36. Throwing pace is important for javelin throw, and the quality of throwing pace could affect the speed of the javelin. In this study, we compared the kinematic parameters of the throwing pace of Zhaocun Zheng and the data of the world's elite javelin throwers. It is important to find the technical gap between the javelin athletes in this field and provide the basis for the javelin throw technique improvement for Chinese coaches and athletes.

\section{Methods}

Based on the researches on Zhaocun Zheng, an outstanding javelin thrower from Taiwan, China. This study analyzed the data about his throwing in the World University Games. Literature method, mathematical statistics, technical image analysis method, and comparative analysis of exercise parameters were used in this study.

Zheng's throwing pace was the hybrid throwing pace between the leaping and running. The supporting leg pushed off the ground forcefully and the swinging leg swinged forward powerfully. The trajectory of human body center of gravity was relatively steady. The step length and the time of each step were appropriate. The aim was to complete the action of withdrawing javelin and finish the preparation before the final thrust, not losing too much horizontal speed from the run-up.

\section{Results}

\subsection{The body caster angle of throwing pace}

Body caster angle of throwing pace is the angle that the body lined backwards when starting the throwing pace. The angle can show whether the movement of an athlete is reasonable. The size and the stability of the angle directly influence the link between the run-up and the action the body surmounts the equipment. The final force of the action to throw the javelin relatively is fixed, so the throwing pace play an important role in convergence of the javelin throwing process and influence the quality from run-up to javelin throwing. 
Table 1 Technical Traits of Zhaocun Zheng's Throw Pace

\begin{tabular}{ccccccccc}
\hline Recor & & \multicolumn{6}{c}{ throwing step torso caster angle $\left({ }^{\circ}\right)$} & $\begin{array}{c}\text { Left } \\
\text { d }\end{array}$ \\
\cline { 3 - 6 }$(\mathrm{m})$ & per & $\begin{array}{c}\text { First } \\
\text { step }\end{array}$ & $\begin{array}{c}\text { Second } \\
\text { step }\end{array}$ & $\begin{array}{c}\text { Third } \\
\text { step }\end{array}$ & $\begin{array}{c}\text { Fourth } \\
\text { step }\end{array}$ & $\begin{array}{c}\text { Max-imum } \\
\text { angle }\left({ }^{\circ}\right)\end{array}$ & $\begin{array}{c}\text { torso and } \\
\text { arms stretch } \\
\text { angle }\left({ }^{\circ}\right)\end{array}$ & $\begin{array}{c}\text { torso } \\
\text { force } \\
\text { angel }\left({ }^{\circ}\right)\end{array}$ \\
\hline 91.36 & 1 & $13^{\circ}$ & $15^{\circ}$ & $24^{\circ}$ & $20^{\circ}$ & $158^{\circ}$ & $90^{\circ}$ & $21^{\circ}$ \\
\hline
\end{tabular}

Table 2 Technical Traits of World Elite Javelin Athletes’ Throw Pace

\begin{tabular}{|c|c|c|c|c|c|c|c|c|}
\hline \multirow{2}{*}{$\begin{array}{l}\text { record } \\
(\mathrm{m})\end{array}$} & \multirow[b]{2}{*}{$\mathrm{n}$} & \multicolumn{4}{|c|}{ throwing step torso caster angle } & \multirow{2}{*}{$\begin{array}{c}\text { Left } \\
\text { Maximum } \\
\text { angle }\left(^{\circ}\right)\end{array}$} & \multirow{2}{*}{$\begin{array}{l}\text { torso and } \\
\text { arms stretch } \\
\text { angle }\left(^{\circ}\right)\end{array}$} & \multirow{2}{*}{$\begin{array}{c}\text { torso } \\
\text { force } \\
\left.\text { angel ( }{ }^{\circ}\right)\end{array}$} \\
\hline & & First step & $\begin{array}{l}\text { Second } \\
\text { step }\end{array}$ & $\begin{array}{l}\text { Third } \\
\text { step }\end{array}$ & $\begin{array}{l}\text { Fourth } \\
\text { step }\end{array}$ & & & \\
\hline $\begin{array}{c}91.90 \pm \\
5.18\end{array}$ & 8 & $6.0 \pm 5.53$ & $6.6 \pm 5.23$ & $\begin{array}{c}20.2 \pm \\
7.65\end{array}$ & $\begin{array}{c}21.0 \pm \\
6.49\end{array}$ & $162.5 \pm 8.49$ & $90.0 \pm 5.55$ & $21.0 \pm 6.49$ \\
\hline
\end{tabular}

The caster angles of Zheng's first and second step separately were $13^{\circ}$ and $15^{\circ}$, and those of the world's best athletes were $6.0^{\circ}$ and $6.6^{\circ}$, from which we could see an obvious gap $(\mathrm{P}<0.01)$ and the differences were $7^{\circ}$ and $8.4^{\circ}$ respectively.(Table $1 \& 2$ ) That shows that Zheng's body caster angle was too large when the first and second throwing pace withdraw javelin, resulting in the body's support effect being significantly weakened, legs moving forward too fast, the supporting leg landing too far on the ground, landing break too large. So the horizontal speed gained in run-up loss, more which in turn affects the tempo of the throwing pace, as well as the velocity and range of cross steps.

The third step of throwing pace was the most important---crossing step. This is the key pace to link run-up and final force. It mission was to further complete the body's twist and form a reasonable backward position while keeping the body's fast moving. The whole process was to create strong conditions for the final force. The changes of Zheng's body caster angle of second-to-third step was $9^{\circ}$ and that of the world's best athletes was $13.6^{\circ}$ on average (Table 3). The difference was greatly obvious $(\mathrm{P}<0.05)$. That means the movement range and velocity of the best athlete was higher than that of Zheng's and the tempo of throwing pace of the former was more reasonable. The large body caster angle of the first and second step of Zheng limited the right leg to swing forward and the left leg to pedal the ground, leading less changes of body caster angle in second-to-third step. The result was to delay the stretching time of the body muscle and reduce muscle contraction force.

Table 3The changes of trunk angle of Zhaocun Zheng and World elite male javelin athletes at the throwing phase

\begin{tabular}{ccccc}
\hline Athlete & Per & Step 1 to 2 & Step 2 to 3 & Step 3 to 4 \\
\hline Zhaocun Zheng & 1 & 2 & 9 & -4 \\
World's elite athlete & 8 & $0.6 \pm 4.11$ & $13.6 \pm 6.57$ & $0.8 \pm 5.38$ \\
\hline
\end{tabular}

The body caster angle of third-to-fourth step of Zheng decreased $4^{\circ}$, but that of the world's best athletes almost had no change. The reason was that the first and second throwing steps make the body back forward too much and speed up the leg's movement during cross steps, which made the right leg too straight when landing the ground and the left leg not actively swing forward and pressed down, increasing the difficulty to keep body leaning back. Therefore, in the process of training, it must be recognized that the skill of throw javelin is a complete process and every technical link is related to each other and influences each other. Too much emphasis on the importance of a certain technical link will affect the whole process of throwing in varying degrees, which will affect the overall technical process. 


\subsection{Analysis on the contrasts of the Torso force angle, flexion angle of left knee and Drawing angle}

The Torso force angle is an angle formed by the torso and the vertical plane, that is the angle of the connection of the mid-points of the shoulders and the hips to the vertical plane. It indicates the working length of the torso and the functioning range of the muscles of the torso. It could be concluded that there are no differences between Zhaocun Zheng, the excellent javelin throwers, and other skilled javelin throwers in the world.(Table 3) If the flexion angle of left knee was less than the average level that the skilled javelin throwers keep in the world, it means the brace on the left side of the throwers was not fixed enough to deliver the strength to the upper limbs effectively, which putted a negative influence on the initial speed of javelin. The drawing angle was an angle formed by the upper part of the throwing arm and the vertical plane, which was considered as the judgement of the range of the strength. Javelin can get about $70 \%$ of the speed in this session. At the final step, the task is to make javelin get its maximum speed by run-up in a certain range. However, there are no obvious differences on this norm between Zhaocun Zheng, the excellent javelin throwers, and other skilled javelin throwers in the world.

\section{Conclusion}

The torso obliquity on the 1 and 2 steps for Zhaocun Zheng ,the excellent javelin thrower, is too much. As the drawing action is mainly completed by the turn-round to the right side, it is suggested that keeping up-right and not suitable to get a longer muscle length by leaning back too early. This action can limit the range of the forward swing of the right leg and the thrust of the left leg, causing little change in the range of the flexion angle of the torso. In that case, the time to pull the muscles longer increases and the strength is reduced.

The flexion angle of left knee of Zhaocun Zheng, the excellent javelin thrower, is less than the average level the skilled javelin throwers keep in the world, it means the brace on the left side of the he is not fixed enough to transform the strength of the body in run-up into the flexibility of muscle. As the shrink of the muscles and the transition of the strength is reduced, the speed of the javelin at the launch step is influenced.

Javelin-throwing is a skill-complicated and fast-strength project In track and field sports, proper skills of javelin throwing require athletes to release the power of the human body in the fast run-up. As a result, it is important to fully realize the technique of javelin is a complete process in the training process, while every part is connected and influenced by each other. Overmuch emphasis on the importance on a certain segment can influence the whole process in several ranges, which is negative for the performance of the skills in general.

\section{References}

[1] Yuan Zuosheng, Nan Zhong Xi. The scientific training method of modern track and field sports [M]. Beijing; people's sports press, 1996:405-412

[2] Kanglize. Types and characteristics of run-up speed of elite male javelin athletes in China. [J] .Journal of Xi'an Institute of physical Education

[3]MA Yongzzhan.Analysis of throwing pace technique of javelin athletes in China. [J] .Chinese sports science and technology 9: 40-41.

[4]Wang Lin. Research on the technology of left leg in the final exertion of Chinese Elite Women Javelin Athletes [J]. Journal of Beijing Sport University, 1997,20 (3):73-78

[5]Wenchao. Advanced course in track and Field. [Beijing: people's Sports Press 2002: 563-575

[6]Wang Qian. Biomechanical analysis of javelin throwing technique in 1995 World Athletics Championships. [J] .track and field 1997: 2: 16-19 